\title{
Measurement of the carbon 14 activity at natural level in air samples
}

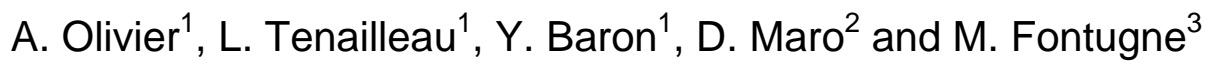 \\ ${ }^{1}$ Marine Nationale, École des Applications Militaires de l'Énergie Atomique, Département \\ Groupe d'Études Atomiques, BP. 19, 50115 Cherbourg Armées, France \\ ${ }^{2}$ Institut de Radioprotection et de Sûreté Nucléaire, Laboratoire de Radioécologie de \\ Cherbourg-Octeville, 50130 Cherbourg-Octeville, France \\ ${ }^{3}$ Laboratoire des Sciences du Climat et de l'Environnement, UMR 1572-CEA/CNRS, \\ Domaine du CNRS, 91198 Gif-sur-Yvette, France
}

\begin{abstract}
The aim of the study was to measure the carbon 14 activity at natural level in air samples using classical methods of radiochemistry and beta counting. Three different methods have been tested in order to minimise the detection limit. In the three methods, the first step consists in trapping the atmospheric carbon 14 into $\mathrm{NaOH}(1 \mathrm{~N})$ using a bubbling chamber. The atmospheric carbon dioxide reacts with $\mathrm{NaOH}$ to form $\mathrm{Na}_{2} \mathrm{CO}_{3}$. In the first method the $\mathrm{Na}_{2} \mathrm{CO}_{3}$ solution is mixed with a liquid scintillate and is directly analysed by liquid scintillation counting (LSC). The detection limit is approximately $0.3 \mathrm{~Bq} \cdot \mathrm{m}^{-3}$ of air samples. The second method consists in evaporating the carbonate solution and then counting the solid residue with a proportional gas circulation counter. The detection limit obtained is equivalent to the first method (0.36 Bq.m ${ }^{-3}$ of air samples). In the third method, $\mathrm{Na}_{2} \mathrm{CO}_{3}$ is precipitated into $\mathrm{CaCO}_{3}$ in presence of $\mathrm{CaCl}_{2} \cdot \mathrm{CaCO}_{3}$ is then analysed by LSC. This method appears to be the most appropriate, the detection limit is $0.04 \mathrm{~Bq} \cdot \mathrm{m}^{-3}$ of air samples.
\end{abstract}

\section{INTRODUCTION}

Besides the natural cosmic-ray induced production of radiocarbon in the atmosphere, ${ }^{14} \mathrm{C}$ also results from nuclear weapons testing and the nuclear power industry. The main part of the ${ }^{14} \mathrm{C}$ discharged from nuclear reactor is produced through neutron-induced reactions and is released as airborne effluents through the ventilation system of the plant to the surrounding environment [1-2]

The atmospheric carbon 14 near the nuclear installations of the French Navy have to be measured from 2005. The laboratory of “Groupe d'Etudes Atomiques” have experimented a technique of carbon tracking in order to determine the efficiency of the method. Next, three techniques of atmospheric radiocarbon measurements have been studied. The aim was to detect the natural level in order to estimate the impact in the environment of the radiocarbon released by the nuclear installation.

\section{EQUIPMENT AND METHOD}

\subsection{Forms of radiocarbon gases analysed}

The emission rate and chemical composition of the released ${ }^{14} \mathrm{C}$ depends on the type and capacity of a given reactor. Several publications discuss various aspects of ${ }^{14} \mathrm{C}$ production rate of nuclear installations [1,3]. In this study, we investigated chemical forms such as $\mathrm{CO}_{2}$ and $\mathrm{CH}_{4}$. 


\subsection{Method of carbon 14 tracking}

A carbon 14 collector (HAG 7000) made by SDEC France company is used for the trapping of the atmospheric carbon 14 . The working principle is shown on the figure 1 . Carbon 14 is trapped in a soda solution $(1 \mathrm{~N})$ prepared a few hours before sampling to avoid the formation of sodium carbonate by air $\mathrm{CO}_{2}$ reaction. The $\mathrm{CO}_{2}$ is directly trapped into the first and the second bottles. The organic carbon is oxidized in the oven by a palladium catalyst held at $450^{\circ} \mathrm{C}$ to form $\mathrm{CO}_{2}$ which is trapped in the third and fourth bottles. The air is passed through $\mathrm{NaOH}$ bubblers at the rate of $20 \mathrm{~L}^{-\mathrm{hr}^{-1}}$. The liquid solution is collected weekly. After 1 week of bubbling, the components of the solution are sodium hydroxide and sodium carbonate.

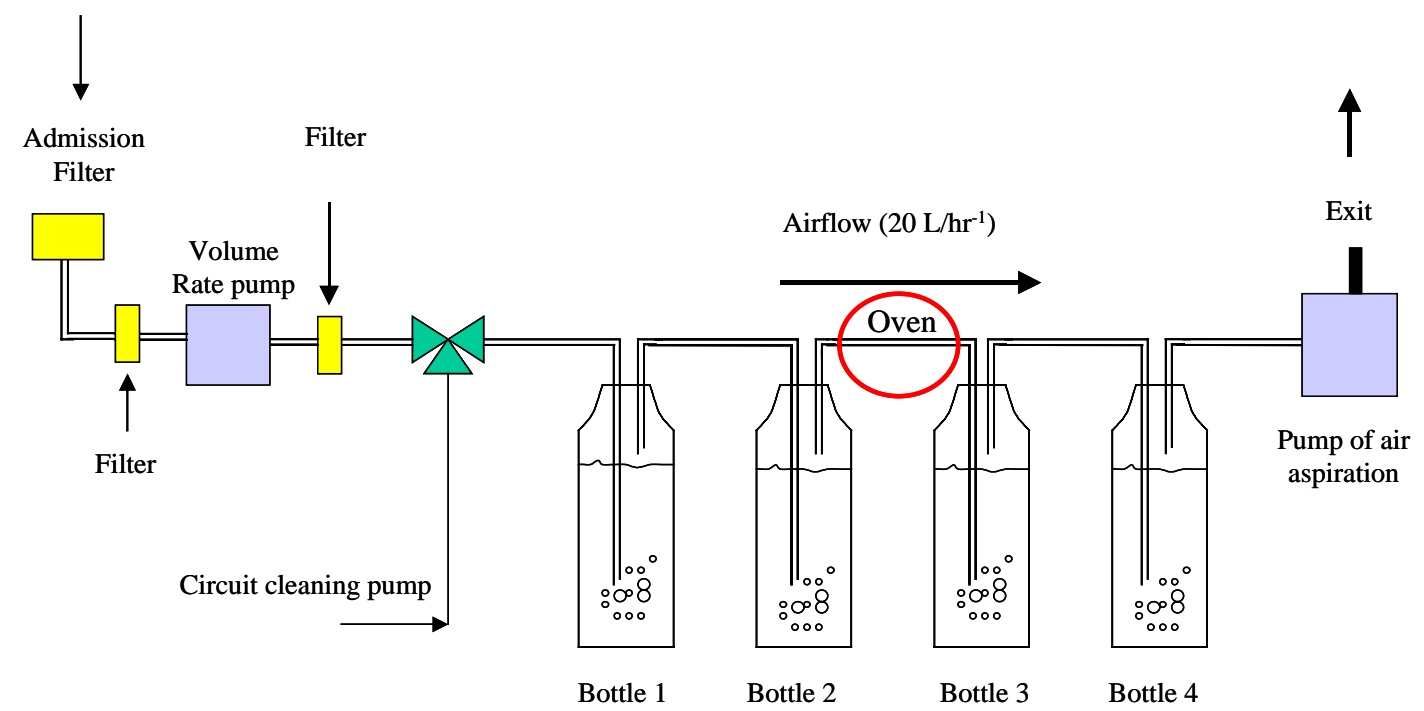

Figure 1. Working principle of carbon 14 collector HAG 7000 (SDEC France).

\subsection{Methods of carbon 14 measurement}

\subsubsection{Measurement of collected solution by liquid scintillation counting}

The collected solution is analysed by time resolved liquid scintillation counting (TR-LSC) with a TriCarb ultra low-level scintillation beta spectrometer (Packard $^{\circledR} 2770$ TR/SL). The concept of the background reducing is based on a type of pulse shape/duration analysis [4]. The measurements are made in the French Navy's low level background laboratory at Cherbourg (Roule Laboratory).

We used the following procedure to set up the spectrometer for ${ }^{14} \mathrm{C}$ activity measurements:

- The counting geometry is a mixture of $1 \mathrm{~mL}$ of each bottle with $10 \mathrm{~mL}$ of scintillator placed in a $20 \mathrm{~mL}$ PTFE low level vial. 1,2,4-trimethylbenzene (Hionic Fluor - Packard ${ }^{\circledR}$ ) is chosen as the scintillator because of its slightly alkalinity ( $\mathrm{pH}$ approximately 7.5). In an acidic medium, sodium carbonate reacts with acid and releases $\mathrm{CO}_{2}$ and therefore carbon 14 as ${ }^{14} \mathrm{CO}_{2}$. The vials are inserted in the Packard vial holders.

- For the selection of the standard and background samples, we decided to use carbonate sodium as the modern activity standard and as background level, we used soda solution $(1 \mathrm{~N})$.

- Spectra of modern standard and background were collected to determine the counting window for ${ }^{14} \mathrm{C}$ measurement. The window was optimised by using the tSIE / AEC mode 
(transform Spectral Index of the External standard / Automatic Efficiency Control) of the Packard Instrument and set to $10-70 \mathrm{keV}$ in order to delete the interference of tritium, which gives a total efficiency of $75 \%$ (Figure 2).

- The variation of the quenching may cause changes of detection efficiency. The quench indicating parameter tSIE is measured for the different analysed samples.

- $\quad$ The data are collected for 12 hrs.

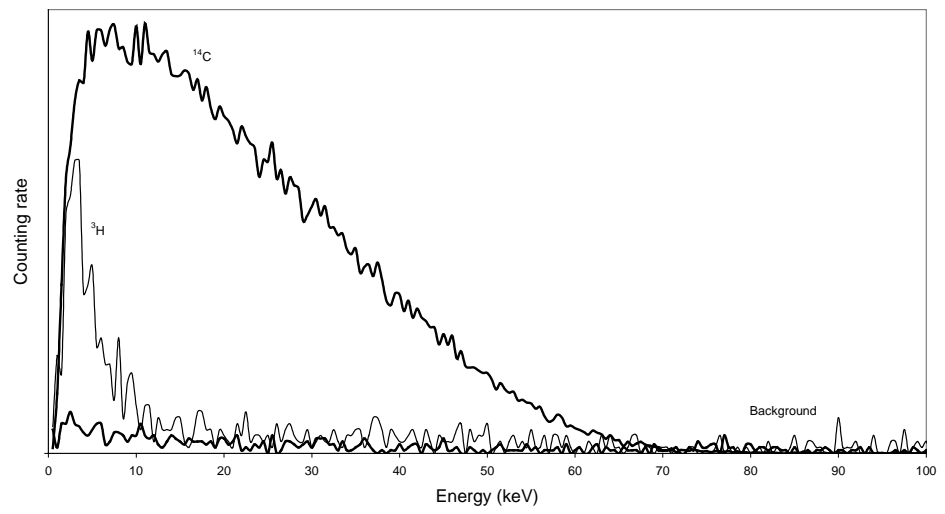

Figure 2. Determination of counting window for $1 \mathrm{~mL}$ of collected solution with $10 \mathrm{~mL}$ of scintillator.

\subsubsection{Measurement of calcium carbonate precipitate by liquid scintillation counting}

In the first bottle, calcium carbonate is precipitated by the reaction of sodium carbonate and calcium chloride. Calcium carbonate precipitate is filtered, rinsed with distilled water and dried at $70^{\circ} \mathrm{C}$. The measurement is made in the Roule Laboratory.

- The counting geometry is a mixture of $1 \mathrm{~g}$ of calcium carbonate with $10 \mathrm{~mL}$ of scintillator (PermaFluor - Packard ${ }^{\circledR}$ ) placed in a $20 \mathrm{~mL}$ PTFE low level vial.

- For the selection of the standard, we decided to prepare calcium carbonate as the modern activity standard. Calcium carbonate standard is precipitated by the reaction of a mixture of sodium carbonate standard / sodium carbonate solution and calcium chloride solution. As background level, we used geological calcium carbonate.

- Spectra of modern standard and background were collected to determine the counting window for ${ }^{14} \mathrm{C}$ measurement. The window was set to $18-70 \mathrm{keV}$ in order to delete the interference of tritium, which gives a total efficiency of $23 \%$.

- The variation of the quenching may cause changes of detection efficiency. The quench indicating parameter tSIE is measured for the different analysed samples.

- $\quad$ The counting time for each sample is $12 \mathrm{hrs}$.

\subsubsection{Measurement of evaporated solution by gas proportional beta counting}

A collected solution's aliquot of the first bottle is evaporated on a stainless steel counting planchet (diameter $20 \mathrm{~cm}^{2}$ ) and then analysed with a gas proportional counter (Canberra ${ }^{\circledR}-$ NU20). The measurement is made in the Roule laboratory (low-background beta $<0.3 \mathrm{cpm}$ for a $55 \mathrm{~mm}$ detector).

- The chamber is filled with counting gas made by $90 \%$ argon and $10 \%$ methane.

- Counting efficiency for ${ }^{14} \mathrm{C}$ particle is determined by evaporation of the first bottle aliquot after addition of a small volume of modern standard $\mathrm{Na}_{2} \mathrm{CO}_{3}$. As background level, an identical volume of sodium hydroxide $1 \mathrm{~N}$ is evaporated.

- The data are collected for a minimum of 12 hours. 


\section{RESULTS AND DISCUSSION}

\subsection{Efficiency of the tracking method of carbon 14}

After one week of collection of air environment, the trapping efficiency of carbon 14 as ${ }^{14} \mathrm{CO}_{2}$ is determined for the first couple of bottles. Barium carbonate is precipitated by the reaction of sodium carbonate and barium chloride. The barium carbonate precipitate is filtered, rinsed with distilled water, dried at $70^{\circ} \mathrm{C}$ and weighed. From the weight of precipitate, we calculated the mass of tracking carbon and compared it with the quantity of collected $\mathrm{CO}_{2}$. The amount of $\mathrm{CO}_{2}$ present in the air measured with a LICOR analyser of ${ }^{2} \mathrm{LRC}$ was approximately $400 \mathrm{ppm}$ that means $0.22 \mathrm{~g}$ of carbon per $\mathrm{m}^{3}$ of air. The collection is repeated several times. The efficiency of tracking is reported in Table 1. The percentages of efficiency higher than $100 \%$ can be explained by the variation of the amount of $\mathrm{CO}_{2}$ near the place of air collection. In fact, $87 \%$ of carbon as $\mathrm{CO}_{2}$ form is tracked in the first bottle.

Table 1. HAG7000 collector $\mathrm{CO}_{2}$ tracking efficiency.

\begin{tabular}{|c|c|c|c|c|}
\hline $\begin{array}{c}\text { Collected } \\
\text { volume } \\
\text { (L) }\end{array}$ & $\begin{array}{c}\text { Theoretical mass of } \\
\text { barium carbonate } \\
\text { precipitate (g) }\end{array}$ & $\begin{array}{c}\text { Experimental mass of } \\
\text { barium carbonate precipitate } \\
\text { in the first bottle (g) }\end{array}$ & $\begin{array}{c}\text { Experimental mass of barium } \\
\text { carbonate precipitate in the } \\
\text { second bottle (g) }\end{array}$ & $\begin{array}{c}\text { Tracking } \\
\text { efficiency } \\
\text { (\%) }\end{array}$ \\
\hline 3348 & 12.12 & 11.02 & 1.04 & 100 \\
\hline 3345 & 12.15 & 10.56 & 1.79 & 102 \\
\hline 3335 & 12.01 & 10.51 & 1.82 & 102 \\
\hline 3350 & 12.12 & 10.63 & 2.00 & 104 \\
\hline
\end{tabular}

In order to determine the efficiency of carbon tracking as methane, we used a standard mixture of methane in nitrogen. The collection is repeated several times. The efficiency of oxidisation of organic carbon is $94 \%$ and $87 \%$ of carbon as $\mathrm{CH}_{4}$ form is tracked in the third bottle (Table 2).

Table 2. HAG7000 collector oven oxidizing efficiency.

\begin{tabular}{|c|c|c|c|c|}
\hline $\begin{array}{c}\text { Collected } \\
\text { volume } \\
(\mathrm{L})\end{array}$ & $\begin{array}{c}\text { Theoretical mass of } \\
\text { barium carbonate } \\
\text { precipitate (g) }\end{array}$ & $\begin{array}{c}\text { Experimental mass of } \\
\text { tracked carbon in the } \\
\text { first bottle (g) }\end{array}$ & $\begin{array}{c}\text { Experimental mass of } \\
\text { tracked carbon in the second } \\
\text { bottle (g) }\end{array}$ & $\begin{array}{c}\text { Oven oxidizing } \\
\text { efficiency (\%) }\end{array}$ \\
\hline 100 & 0.88 & 0.73 & 0.07 & 91 \\
\hline 100 & 0.88 & 0.75 & 0.10 & 97 \\
\hline 200 & 1.77 & 1.49 & 0.20 & 95 \\
\hline 300 & 2.65 & 1.97 & 0.43 & 91 \\
\hline
\end{tabular}

\subsection{Detection limit for the method of radiocarbon measurement}

The detection limit is calculated for the different methods of measurement in the first bottle because of its high tracking efficiency of carbon 14 as $\mathrm{CO}_{2}$ form.

\subsubsection{Measurement of collected solution by liquid scintillation counting}

The variation of the quenching may cause changes of detection efficiency. The quench indicating parameter tSIE is measured for the different analysed samples. The tSIE parameter uses the interaction between the radioactivity from an external ${ }^{133} \mathrm{Ba}$ source and the scintillator in the sample vial to determine quench level. The concentration of soda solution have no influence on the tSIE value and therefore no quenching correction is needed for collected solution (Table 3). 
Table 3. tSIE parameter of different solutions analysed by LSC.

\begin{tabular}{|c|c|c|c|}
\hline Sample & Sample volume $(\mathrm{mL})$ & Scintillator volume $(\mathrm{mL})$ & tSIE \\
\hline $\mathrm{NaOH} 1 \mathrm{~N}$ & 1 & 10 & 370 \\
\hline $\mathrm{NaOH} 0.6 \mathrm{~N} / \mathrm{Na}_{2} \mathrm{CO}_{3} 0.2 \mathrm{~N}$ & 1 & 10 & 362 \\
\hline $\mathrm{NaOH} 0.28 \mathrm{~N} / \mathrm{Na}_{2} \mathrm{CO}_{3} 0.36 \mathrm{~N}$ & 1 & 10 & 368 \\
\hline $\mathrm{Na}_{2} \mathrm{CO}_{3} 0.5 \mathrm{~N}$ & 1 & 10 & 367 \\
\hline Collected solution & 1 & 10 & 381 \\
\hline
\end{tabular}

The detection limit is calculated from the measurement of the background level in the energy window of the ${ }^{14} \mathrm{C}(1.6 \mathrm{cpm})$. The calculated detection limit is $0.33 \mathrm{~Bq} \cdot \mathrm{m}^{-3}$ of collected air by application of the different parameters: a counting time of $720 \mathrm{~min}$, a counting efficiency of $75 \%$, a collected volume of $3.5 \mathrm{~m}^{3}$, a bottle volume of $160 \mathrm{~mL}$ and a tracking efficiency of $87 \%$ (bottle 1). The natural level of carbon 14 in air is $248 \mathrm{~Bq} / \mathrm{kg} \mathrm{C} \mathrm{[5]} \mathrm{equivalent} \mathrm{to} 0.05 \mathrm{~Bq} \cdot \mathrm{m}^{-3}$.

\subsubsection{Measurement of calcium carbonate precipitate by liquid scintillation counting}

The quench indicating parameter tSIE is measured for $1 \mathrm{~g}$ of precipitate mixed with $10 \mathrm{~mL}$ of scintillator. The results are reported in table 4.

Table 4. tSIE parameter of different precipitates.

\begin{tabular}{|c|c|c|c|}
\hline Sample & Weight $(\mathrm{g})$ & Scintillator volume $(\mathrm{mL})$ & tSIE \\
\hline Geological calcium carbonate & 1 & 10 & 982 \\
\hline Precipitate of collected solution & 1 & 10 & 1130 \\
\hline Standard precipitate of collected solution & 1 & 10 & 1140 \\
\hline
\end{tabular}

The tSIE of the precipitate obtained from collected solution are higher than the tSIE of the geological calcium carbonate. This is explained by the presence of $22 \%$ of calcium hydroxide in the analysed precipitate of collected solution. Indeed, the reaction of sodium hydroxide with $\mathrm{CO}_{2}$ is not complete after 1 week $\left(3.5 \mathrm{~m}^{3}\right.$ ) of bubbling (Figure 3 ).

The detection limit is calculated from the measurement of the background level in the energy window $18-70 \mathrm{keV}(1.8 \mathrm{cpm})$. The calculated detection limit is $0.04 \mathrm{~Bq} / \mathrm{m}^{3}$ of collected air by application of the different parameters: a counting time of $720 \mathrm{~min}$, a counting efficiency of $23 \%$, a collected volume of $3.5 \mathrm{~m}^{3}$ and a calcium carbonate precipitate of $0.78 \mathrm{~g}$ (bottle 1). The detection limit is equivalent to the natural level of carbon 14 in air.

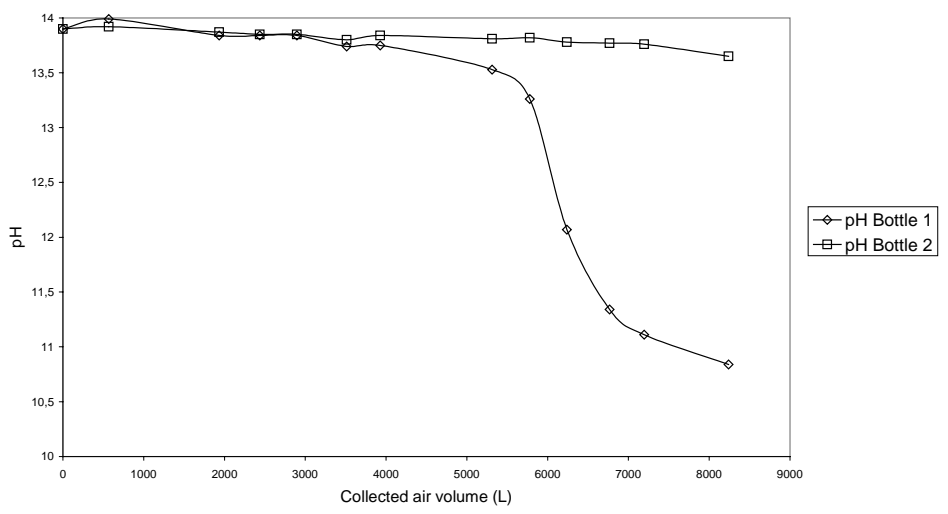

Figure 3. pH of collected solution as a function of collected air volume. 


\subsubsection{Measurement of evaporated solution by gas proportional beta counting}

A collected solution's aliquot of the first bottle is evaporated on a stainless steel counting planchet and then analysed with a gas proportional counter. Counting efficiency for ${ }^{14} \mathrm{C}$ particles is determined by evaporation of the first bottle aliquot after addition of a small volume of modern standard $\mathrm{Na}_{2} \mathrm{CO}_{3}$. As background level, an identical volume of hydroxide sodium $1 \mathrm{~N}$ is evaporated. The counting efficiency is a function of the evaporated volume and varies between $3 \%$ to $13 \%$ (Figure 4).

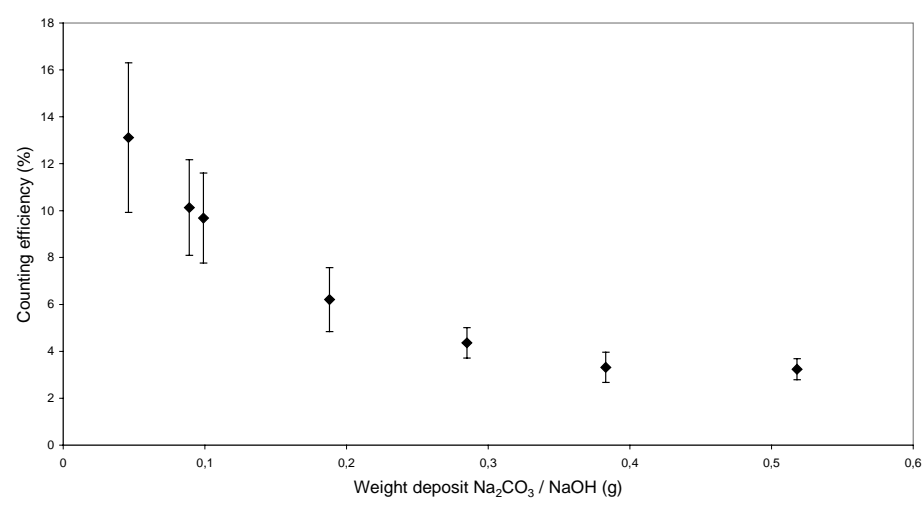

Figure 4. Counting efficiency as a function of deposit weight.

The calculated detection limit is $0.36 \mathrm{~Bq} \cdot \mathrm{m}^{-3}$ of collected air by application of the different parameters: a counting time of $12 \mathrm{hrs,} \mathrm{a} \mathrm{counting} \mathrm{efficiency} \mathrm{of} 10 \%$, a collected volume of $3.5 \mathrm{~m}^{3}$ and a deposit weight of $0.1 \mathrm{~g}$ (bottle 1 ).

\section{CONCLUSION}

The efficiency of carbon 14 tracking in soda solution by HAG7000 collector is 100\%. The tracking of carbon as $\mathrm{CO}_{2}$ form occurs mainly in the first bottle (87\%) and as organic form in the third bottle (87\%). The furnace oxidizing efficiency is near $94 \%$.

Three techniques of carbon 14 measurement have been tested by collecting air environment. The direct analysis by LSC of collected solution in presence of scintillator gives a detection limit of $0.33 \mathrm{~Bq} / \mathrm{m}^{3}$. The evaporation of a collected solution's aliquot on a stainless steel counting planchet, analysed with a gas proportional counter, produces a detection limit of $0.36 \mathrm{~Bq} / \mathrm{m}^{3}$. The most appropriate technique is the precipitation of calcium carbonate. The analysis of $\mathrm{CaCO}_{3}$ precipitate, formed by adding calcium chloride to the collected solution, ensures to reach the natural level of atmospheric carbon $14\left(0.05 \mathrm{~Bq} / \mathrm{m}^{3}\right)$.

\section{References}

[1] Kunz C., Carbon-14 discharge at three light water reactors. Health Physics 49, 1 (1985) 25-35.

[2] Stenström K., Erlandsson B., Hellborg R., Wiebert A., Skog G., Vesanen R., Alpsten M., Bjurman B., A one-year study of the total air-borne ${ }^{14} \mathrm{C}$ effluents from two Swedish light-water reactors, one boiling water- and one pressurized water reactor, Journal of Radioanalytical and Nuclear Chemistry 198, 1 (1995) 203-213.

[3] Levin I., Kromer B., Barabas M., Münnich K. O., Environmental distribution and long-term dispersion of reactor ${ }^{14} \mathrm{CO}_{2}$ around two German nuclear power plants, Heath Physics 54, (1988) 149-156.

[4] Van Cauter S., Three dimension spectrum analysis: A new approach to reduce background of liquid scintillation counters, Packard Applications Bulletin 006, (1986).

[5] Maro D., Fontugne M., Hatté C., Hebert D., Rozet M., ${ }^{14} \mathrm{C}$ sources and distribution in the vicinity of the Hague nuclear processing plant: Part II-Marine environment, Radiocarbon 46, 2 (2004) 831-839. 